\title{
How the introduction of OSCEs has affected the time students spend studying: results of a nationwide study
}

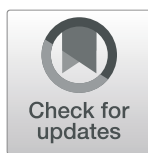

Stefan Müller ${ }^{1}$, Ines Koch ${ }^{2}$, Utz Settmacher ${ }^{1}$ and Uta Dahmen ${ }^{3^{*}}$ (D)

\begin{abstract}
Background: Medical schools globally now use objective structured clinical examinations (OSCEs) for assessing a student's clinical performance. In Germany, almost all of the 36 medical schools have incorporated at least one summative OSCE into their clinical curriculum. This nationwide study aimed to examine whether the introduction of OSCEs shifted studying time. The authors explored what resources were important for studying in preparation for OSCEs, how much time students spent studying, and how they performed; each compared to traditionally used multiple choice question (MCQ) tests.

Methods: The authors constructed a questionnaire comprising two identical sections, one for each assessment method. Either section contained a list of 12 study resources requesting preferences on a 5-point scale, and two open-ended questions about average studying time and average grades achieved. During springtime of 2015, medical schools in Germany were asked to administer the web-based questionnaire to their students in years 3-6. Statistical analysis compared the responses on the open-ended questions between the OSCE and MCQs using a paired $t$-test.

Results: The sample included 1131 students from 32 German medical schools. Physical examination courses were most important in preparation for OSCEs, followed by class notes/logs and the skills lab. Other activities in clinical settings (e.g. medical clerkships) and collaborative strategies ranked next. Conversely, resources for gathering knowledge (e.g. lectures or textbooks) were of minor importance when studying for OSCEs. Reported studying time was lower for OSCEs compared to MCQ tests. The reported average grade, however, was better on OSCEs.

Conclusions: The study findings suggest that the introduction of OSCEs shifted studying time. When preparing for OSCEs students focus on the acquisition of clinical skills and need less studying time to achieve the expected level of competence/performance, as compared to the MCQ tests.
\end{abstract}

Keywords: Assessment, OSCEs, Study behaviour, Medical students, Survey

\section{Background}

Medical schools around the world have implemented objective structured clinical examinations (OSCEs) [1]. In an OSCE, students move through a series of stations where they have to perform specific clinical tasks within a time limit. The content domains to be assessed and the scoring scheme for the examination are defined in advance [2]. Since its first description in the mid-1970s [3], the OSCE has been the subject of countless papers

\footnotetext{
* Correspondence: uta.dahmen@med.uni-jena.de

${ }^{3}$ Department of General, Visceral and Vascular Surgery, Experimental

Transplantation Surgery, Universitätsklinikum Jena, Drackendorfer Str. 1, 07747 Jena, Germany

Full list of author information is available at the end of the article
}

[4]. A number of papers have shown that the OSCE is a valid and reliable assessment of a student's clinical competence [5-8]. Papers have also shown that students accept the OSCE as a relevant and fair exam [9-11].

However, only a few studies exist on how the deployment of OSCEs affects students' study behaviour. Newble and Jaeger [12], for instance, reported that work-based learning, textbooks, tutorials, and group activities were the predominant resources when studying for a clinical examination. Mavis [13] found that students focused on cognitive learning strategies, such as reviewing textbooks or class notes, when preparing for an OSCE. This study, however, was limited to the extent that the

(c) The Author(s). 2019 Open Access This article is distributed under the terms of the Creative Commons Attribution 4.0 International License (http://creativecommons.org/licenses/by/4.0/), which permits unrestricted use, distribution, and reproduction in any medium, provided you give appropriate credit to the original author(s) and the source, provide a link to the Creative Commons license, and indicate if changes were made. The Creative Commons Public Domain Dedication waiver (http://creativecommons.org/publicdomain/zero/1.0/) applies to the data made available in this article, unless otherwise stated. 
examined OSCE was a formative, and not a summative assessment, which may explain the different findings. Rudland and colleagues [14] identified that the OSCE fostered collaborative learning, but did not encourage students to spend more time learning in clinical settings. The disparities found in the literature suggest that the OSCE does not always drive student learning in the desirable way. The student study behaviour may rather depend upon of what is specifically assessed in the OSCEs, the purpose of the assessment (summative vs. formative), as well as other factors such as patient availability [15], advice given by the teachers or information from peers.

The aim of our study was to examine whether the introduction of OSCE assessments shifted the time students spend studying. We explored what resources were important for studying and how much time students spent when studying for OSCEs compared to traditionally used multiple choice question (MCQ) tests, and how they performed on the respective assessment format.

\section{Methods}

\section{Context}

We conducted the present study in the context of the amendment of the national medical licensure act carried out in 2002, which called for a more practiceand patient-oriented alignment of medical education in Germany [16]. Each of the 36 medical schools established before 2012 has a six-year curriculum. The curricula usually consist of two preclinical years followed by three clinical years and, finally, the clinical internship year. According to the guidelines of the medical licensure act, the clinical years comprise 41 predetermined courses entailing the full range of clinical areas or disciplines. During these courses, students have to pass summative (graded) in-house assessments designed by medical school members to be admitted to the national licensing examination. The medical licensure act sets the general framework of the undergraduate programme, but schools have considerable freedom to organise their own curricula. Thus, both the succession of the individual courses and their specific content, as well as the accompanying assessment strategy differ from one school to another.

Written assessments, in the form of MCQ tests, are still most commonly used during the clinical years in all German medical schools. The focus is on testing a student's knowledge about diseases, involving pathogenesis, signs and symptoms, diagnostic approaches, and treatment strategies. In order to comply with the new legal requirements, medical schools have broadened their assessment repertoire to include performance related skills. By now, 33 of the 36 medical schools (92\%) have introduced at least one summative OSCE into their in-house assessment system used for the clinical curriculum [17]. In the held OSCEs, the main focus is on the performance domains physical examination, history taking, practical procedures, and communication skills. Passing the OSCE(s) is also a prerequisite for students to be admitted to the national licensing examination.

\section{Student population}

In the academic year 2014/15, there were around 88,000 medical students in Germany. Almost $2 / 3$ of them $(53,352$ [61\%]) were female students [18]. We surveyed medical schools on both the number of students per year and the timing when OSCEs occurred in the curriculum. With these data, we calculated the proportion of students during the clinical years or the clinical internship year who had exposure to a summative OSCE at slightly more than 32,700 .

\section{Data collection}

Between February and April of 2015, we conducted this study using the free software package SoSci Survey (www.soscisurvey.de). Due to privacy terms, we did not get access to the students' email addresses. We therefore could not administer our web-based questionnaire to a selected sample of the population in study; but instead, asked the medical schools in Germany to advertise the survey on their websites or through messaging systems. All medical students of years $3,4,5$, and 6 , who had undertaken at least one summative OSCE, were eligible to participate in the study. Participation was voluntary and anonymous, and the respondents did not receive any incentive for completing the questionnaire. The study was in accordance with the ethical standards of our institutional review board (Ethics Committee of Jena University Hospital at Friedrich Schiller University).

\section{Design of the questionnaire}

We first reviewed literature and conducted interviews with students to identify items that we could use for our study. Based on this knowledge, we developed a draft questionnaire. As a next step, we repeatedly pilot-tested and revised the draft for ensuring that respondents completed the survey in the intended manner. The final version of the questionnaire comprised two identical sections, the first for the OSCE and the second for the MCQs.

Each section contained a list of 12 study resources (Table 1). Participants rated their preferences in preparation for the respective assessment method on a 5-point scale, anchoring 1 (not important), 2 (slightly important), 3 (moderately important), 4 (important), and 5 (very important). Participants then answered two open-ended questions. Firstly, we prompted them to 
Table 1 Students' preferences of study resources when preparing for OSCEs and MCQ tests

\begin{tabular}{lll}
\hline Study resource & OSCEs & MCQ tests \\
& Mean (SD) & Mean (SD) \\
\hline Physical examination courses & $4.38(0.82)$ & $2.09(1.07)$ \\
Class notes/logs & $3.88(1.11)$ & $4.25(0.95)$ \\
Skills lab & $3.87(1.21)$ & $1.83(0.97)$ \\
Group learning & $3.61(1.26)$ & $2.57(1.29)$ \\
Medical clerkships & $3.58(1.16)$ & $2.48(1.14)$ \\
Clinical work placements & $3.56(1.12)$ & $2.37(1.13)$ \\
Peer tutorials & $3.53(1.19)$ & $2.15(1.11)$ \\
Textbooks & $3.17(1.07)$ & $3.97(0.98)$ \\
Multimedia materials & $3.05(1.11)$ & $3.32(1.19)$ \\
Casebooks & $2.90(1.14)$ & $2.42(1.14)$ \\
Lectures & $2.67(1.08)$ & $4.07(1.03)$ \\
PBL courses & $2.48(1.14)$ & $2.12(1.09)$ \\
\hline
\end{tabular}

PBL problem-based learning, SD standard deviation

The responses were made on a 5-point scale with anchors 1 (not important), 2 (slightly important), 3 (moderately important), 4 (important), and 5 (very important)

Number of respondents, $n=1131$

estimate the average total time they spent preparing for a single summative in-house OSCE or MCQ test. To improve ease of completion, we requested them to indicate their time spent in working days of about $8 \mathrm{~h}$. Secondly, we asked them to report their overall average grade achieved on each of the two assessment methods. In this paper, we present the reported grades on a 4.0 grading scale ranging from 0.0 (failing grade) and 1.0 (lowest passing grade) to 4.0 (best possible grade). Finally, the questionnaire collected demographic details, involving gender, age, academic year (semester), and medical school affiliation.

The questionnaire also included an 11-item set on the benefit of the OSCE or MCQs (at the beginning of each section). The results are presented in a separate paper recently published in GMS Journal for Medical Education [19]. All the questionnaire items can be found in Additional file 1 .

\section{Data analysis}

After sampling, we verified that each respondent had exposure to a summative OSCE by squaring the indicated semester or the day when completing our questionnaire with the specific curriculum of the relevant medical school. For carrying out the statistical analysis, we used IBM SPSS Statistics for Windows, Version 24 (IBM Corp., Armonk, NY, USA). We performed descriptive statistics and used a paired $t$-test to compare participants' responses on the open-ended questions between the OSCE and MCQs. We calculated Cohen's $d$ as a measure of effect size from the $t$-statistic ( $t$-value, group size, and Pearson's correlation coefficient). To determine whether the medical school had an influence on the results, we conducted a univariate ANOVA using the mean of the responses for the two assessment methods (excluding missing data) as the dependent variable and the medical school as the fixed factor. We considered $p$ values below 0.05 statistically significant. When not stated otherwise, we present data as means with standard deviations in parentheses.

\section{Results \\ Sample}

The number of participants who completed the questionnaire was 1189 . We removed 58 respondents, as either the demographic details were incomplete or we observed that those respondents had not yet been exposed to a summative in-house OSCE. Our analysis included 1131 respondents (777 female students [69\%] vs. 354 male students [31\%]) from 32 of the 33 medical schools (97\%) that were holding summative OSCE(s). The sample represented all age groups of students, with a range from 19 to 45 years (median 25). Group sizes of years 4, 5, and 6 were similar (318 [28\%], 338 [30\%], and 303 [27\%], respectively), while the proportion of year 3 due to less exposure to OSCEs was lower (172 [15\%]). The number of respondents in each of the 33 medical schools varied between 0 and 123, with a mean of 34 responses per school, depending on how the individual schools advertised our study (websites vs. messaging systems).

\section{Study resources}

All 1131 respondents included into the analysis completed the list on study resources. The ratings indicated that in preparation for OSCEs, students mostly preferred resources to acquire clinical skills. Physical examination courses (4.38 [0.82]) ranked first, followed by class notes/logs (3.88 [1.11]) and the skills lab (3.87 [1.21]). Medical clerkships (3.58 [1.16]) and clinical work placements (3.56 [1.12]), as well as group learning (3.61 [1.26]) and peer tutorials (3.53 [1.19]) ranked next. The ratings also showed that students attached moderate importance to resources for gathering knowledge, such as lectures (2.67 [1.08]) or textbooks (3.17 [1.07]), when studying for OSCEs.

Students' preferences of resources for studying were different when they were preparing for MCQ tests. Resources to gather knowledge were most important, whereas those to acquire clinical skills were of minor importance. Class notes/logs (4.25 [0.95]), lectures (4.07 [1.03]), and textbooks (3.97 [0.98]) ranked first, second, and third, followed by multimedia materials (3.32 [1.19]). Table 1 shows the complete ratings on the list of study resources for both assessment methods. 


\section{Studying time}

We obtained valid responses from 1043 respondents. The reported number of hours spent for an OSCE was 66.5 (52.5) and 94.8 (71.5) for an MCQ test, respectively, which was significantly different $(t[1042]=-14.78, p<0.01)$. Cohen's $d$ of 0.44 showed an effect size in the medium range.

The ANOVA revealed that the medical school had a significant influence on the duration of studying ( $F[31$, $1011]=5.40, p<0.01$, partial eta squared $=0.14$ ). Table 2 includes the results on studying time by medical school affiliation. We found that respondents from about half of the medical schools (15/32 [47\%]) reported a significantly lower time spent in preparation for an OSCE compared to an MCQ test, while the time spent did not differ significantly between the assessment methods for respondents of the other schools.

\section{Performance outcomes}

From our respondents, 1111 replied to the question about performance outcomes. The reported average grade was $3.13(0.62)$ on OSCEs and 2.84 (0.62) on MCQ tests, respectively. The difference was significant $(t[1110]=$ $12.55, p<0.01)$. Cohen's $d$ effect size was 0.47 indicating a medium effect.

There was a significant influence of the medical school on the OSCE and MCQ grades $(F[31,1079]=$ $6.48, p<0.01$, partial eta squared $=0.16$ ). Table 3 shows the results on performance outcomes by medical school affiliation. Our analysis revealed that the reported grades were significantly better on OSCEs for respondents of almost half of the medical schools (14/32 [44\%]), whereas the grades on MCQ tests were significantly better only in one school (XV).

\section{Discussion}

In response to the amendment of the national licensure act, German medical schools have incorporated OSCEs into their system of assessment. This nationwide study sought to address how the introduction of OSCEs has affected the time students spend studying. We identified that students use different strategies to prepare in advance of OSCE assessments than common MCQ tests. However, this finding was not surprising: When preparing for an assessment, students adapt their study behaviour (what and how they learn) to the assessment rather than to the learning objectives laid down in the curriculum. Both the content domains to be expected and the tasks required in the upcoming assessment influence student learning $[20,21]$, which has been described as pre-assessment learning effects of assessment [22]. Given the tasks being tested in the OSCEs (taking a history, examining a patient or carrying out a procedure), we therefore expected that students seek opportunities to rehearse the desired clinical skills.
Table 2 Reported studying time for OSCEs and MCQ tests by medical school affiliation

\begin{tabular}{|c|c|c|c|c|}
\hline \multirow[t]{2}{*}{$\begin{array}{l}\text { Medical } \\
\text { school }\end{array}$} & \multirow[t]{2}{*}{$n^{b}$} & \multirow{2}{*}{$\begin{array}{l}\text { Time spent (h) } \\
\text { for an OSCE } \\
\text { Mean }\end{array}$} & \multirow{2}{*}{$\begin{array}{l}\text { Time spent } \\
\text { (h) for an } \\
\text { MCQ test }{ }^{a} \\
\text { Mean }\end{array}$} & \multirow[t]{2}{*}{$p^{c}$} \\
\hline & & & & \\
\hline VI & 51 & 51.8 & 87.7 & $<0.01$ \\
\hline VII & 38 & 41.6 & 76.5 & $<0.01$ \\
\hline VIII & 38 & 50.6 & 109.5 & $<0.01$ \\
\hline$x$ & 108 & 89.1 & 146.2 & $<0.01$ \\
\hline$X I$ & 34 & 51.7 & 92.2 & $<0.01$ \\
\hline XII & 32 & 54.3 & 120.6 & $<0.01$ \\
\hline XIV & 72 & 59.9 & 82.0 & $<0.01$ \\
\hline $\mathrm{XVI}$ & 40 & 52.5 & 105.8 & $<0.01$ \\
\hline XXXI & 55 & 46.4 & 80.0 & $<0.01$ \\
\hline$\|$ & 11 & 54.5 & 103.3 & 0.01 \\
\hline III & 17 & 57.2 & 84.7 & 0.01 \\
\hline$X X I I$ & 8 & 85.0 & 156.0 & 0.02 \\
\hline XXIII & 18 & 44.1 & 95.6 & 0.02 \\
\hline XXIV & 38 & 111.8 & 139.8 & 0.02 \\
\hline$X X X \|$ & 50 & 47.9 & 63.7 & 0.04 \\
\hline IX & 33 & 67.9 & 89.7 & 0.06 \\
\hline$X X X$ & 25 & 54.2 & 70.4 & 0.06 \\
\hline V & 16 & 45.5 & 59.5 & 0.07 \\
\hline I & 18 & 53.8 & 79.8 & 0.08 \\
\hline$X X V$ & 6 & 60.0 & 89.3 & 0.08 \\
\hline$X X I$ & 51 & 56.9 & 69.6 & 0.09 \\
\hline XXVIII & 54 & 61.3 & 70.8 & 0.20 \\
\hline IV & 57 & 78.3 & 89.2 & 0.22 \\
\hline XIII & 15 & 70.9 & 92.8 & 0.32 \\
\hline$X X$ & 4 & 62.0 & 46.0 & 0.47 \\
\hline XXVI & 31 & 77.2 & 85.5 & 0.47 \\
\hline XIX & 6 & 121.3 & 149.3 & 0.48 \\
\hline$X V$ & 11 & 49.5 & 56.0 & 0.57 \\
\hline XXIX & 5 & 67.2 & 77.6 & 0.60 \\
\hline$X X V I I$ & 4 & 60.0 & 52.0 & 0.64 \\
\hline$X V I I$ & 95 & 99.3 & 98.7 & 0.90 \\
\hline$X V I I I$ & 2 & 64.0 & 60.0 & 0.91 \\
\hline
\end{tabular}

${ }^{a}$ Average number of hours (h) students reported to study in preparation for a single summative in-house OSCE or MCQ test

${ }^{b}$ Number of responses

${ }^{\mathrm{C}} \mathrm{A}$ paired $t$-test was used

Although other authors have reported similar findings, they only examined one OSCE at a single institution and did not use a multi-centre approach [23, 24].

In conclusion, our findings depicted that the deployment of OSCEs has an impact on the students' learning behaviour. In agreement with previous studies [23-25], the assessment tool encourages students to acquire clinical skills in, for example, physical examination, 
Table 3 Performance outcomes in OSCEs and MCQ tests by medical school affiliation

\begin{tabular}{|c|c|c|c|c|}
\hline \multirow[t]{2}{*}{$\begin{array}{l}\text { Medical } \\
\text { school }\end{array}$} & \multirow[t]{2}{*}{$n^{\mathrm{b}}$} & \multirow{2}{*}{$\begin{array}{l}\text { Average grade } \\
\text { on OSCEs } \\
\text { Mean }\end{array}$} & $\begin{array}{l}\text { Average grade } \\
\text { on MCQ tests }\end{array}$ & \multirow[t]{2}{*}{$p^{c}$} \\
\hline & & & Mean & \\
\hline 1 & 22 & 3.52 & 2.90 & $<0.01$ \\
\hline V & 16 & 3.38 & 2.47 & $<0.01$ \\
\hline $\mathrm{Vl}$ & 52 & 3.53 & 2.73 & $<0.01$ \\
\hline VII & 42 & 3.61 & 3.00 & $<0.01$ \\
\hline IX & 35 & 3.48 & 3.01 & $<0.01$ \\
\hline$X I$ & 34 & 3.26 & 2.86 & $<0.01$ \\
\hline XIV & 72 & 3.12 & 2.76 & $<0.01$ \\
\hline$X X I$ & 54 & 2.89 & 2.60 & $<0.01$ \\
\hline XXIV & 48 & 3.38 & 3.03 & $<0.01$ \\
\hline XXVIII & 58 & 3.37 & 2.54 & $<0.01$ \\
\hline$X X X I$ & 57 & 3.38 & 2.81 & $<0.01$ \\
\hline$X X V I I$ & 4 & 3.75 & 2.13 & 0.01 \\
\hline III & 17 & 3.54 & 3.12 & 0.02 \\
\hline XIII & 15 & 3.40 & 2.93 & 0.02 \\
\hline$X X V$ & 6 & 3.42 & 2.62 & 0.06 \\
\hline$X X I X$ & 5 & 3.60 & 3.00 & 0.07 \\
\hline XXXII & 49 & 3.06 & 2.89 & 0.08 \\
\hline VIII & 39 & 2.96 & 2.79 & 0.09 \\
\hline$X X$ & 4 & 2.50 & 3.00 & 0.09 \\
\hline$X X \|$ & 8 & 3.25 & 3.00 & 0.10 \\
\hline$X V I$ & 43 & 3.24 & 3.08 & 0.13 \\
\hline$X X X$ & 23 & 2.98 & 2.72 & 0.16 \\
\hline$X V I I$ & 105 & 3.05 & 2.95 & 0.19 \\
\hline$X I X$ & 8 & 3.19 & 2.84 & 0.21 \\
\hline$x$ & 122 & 2.60 & 2.66 & 0.38 \\
\hline XII & 33 & 2.81 & 2.71 & 0.38 \\
\hline$X V I I I$ & 2 & 3.25 & 2.75 & 0.50 \\
\hline XXIII & 20 & 3.10 & 3.14 & 0.88 \\
\hline IV & 62 & 2.96 & 2.97 & 0.92 \\
\hline$X X V I$ & 31 & 2.81 & 2.81 & 0.96 \\
\hline$\|$ & 12 & 3.33 & 3.33 & 1.00 \\
\hline$X V$ & 13 & 2.85 & 3.48 & 0.01 \\
\hline
\end{tabular}

${ }^{a}$ Overall average grade across all assessments of that kind as reported by the students. We used a 4.0 grading scale (minimum-maximum, 0.0-4.0)

${ }^{\mathrm{b}}$ Number of responses

${ }^{\mathrm{C}} \mathrm{A}$ paired $t$-test was used

practical procedures or communication. The assessment also appears to motivate students - as compared to the MCQ tests - to focus more on studying in authentic learning environments and the community, both of which has been seen as important to support learning [26, 27].

If students prepare for an OSCE "designed to assess certain competencies or skills" [28]; vs. MCQs, which draw items from a much larger content domain, then they would probably need less study time to achieve the required learning outcomes. Our findings confirmed this assumption for the first time. We found that even though there were differences between schools, students spent less time preparing for an OSCE compared with an MCQ test, and yet performed well.

There has been evidence that scores achieved on the OSCE are strong predictors of a later clinical performance [29, 30]. However, good performance on the OSCE does not necessarily mean a student will have the same level of competence or performance in the clinical workplace. The simulated environment in which the OSCEs take place can influence the performance. Thus, a student might perform poorer when he/she is faced with unexpected, unusual circumstances in the real workplace [31]. It is important to keep this in mind when considering the (good) performance outcomes in OSCEs [28].

\section{Limitations}

Our study has several limitations related to its sample. First, as we chose the sampling design of collecting data from every individual of the studied population by using advertisements, we could not retrace how many of the eligible students we approached. Therefore, we can report neither a response nor a non-response rate. Second, we found an overrepresentation of respondents from particular medical schools in our sample, which might have skewed the results. The varying degree to which the individual medical schools supported our study may have caused this fact. Nevertheless, the demographic profile of our sample reflected the general make-up of the medical student population in Germany and, in addition, we had a sufficiently large sample size for our analysis.

Another limitation of the study is that it relied on a self-reporting instrument to determine study resources, studying time, and performance outcomes leading to potential bias. This needs to be considered when interpreting the results.

\section{Conclusions}

We conclude that the introduction of the OSCE assessment shifted the time students spend studying. In preparation for OSCEs, students focus their attention on acquiring the necessary clinical skills, and they need less study time to achieve the expected level of competence or performance compared with MCQ tests. This clearly confirms the value of adding the OSCE assessment to a testing programme, as it places the emphasis on the acquisition of practical skills in addition to knowledge. 


\section{Additional file}

Additional file 1: Questionnaire items (translated into English). (PDF 238 kb)

\section{Abbreviations}

ANOVA: Analysis of variance; MCQs: Multiple choice questions;

OSCEs: Objective structured clinical examinations

\section{Acknowledgements}

The authors would like to thank the representatives of medical schools for their support, as well as Thomas Kessler from the Department of Social Psychology, University of Jena for his helpful advice on data collection and analysis. A special thanks goes to the students who completed the questionnaire.

\section{Funding}

None.

\section{Availability of data and materials}

The data that support the findings of this study are available from the corresponding author upon reasonable request.

\section{Authors' contributions}

The study was designed and conceptualised by SM, UD, and US. SM, IK, and UD contributed to the acquisition, analysis, and interpretation of the data used for the work. SM was a major contributor in writing the manuscript and all authors read and approved the final manuscript to be published.

\section{Ethics approval and consent to participate}

According to the guidelines of the Ethics Committee of Jena University Hospital at Friedrich Schiller University, no formal ethics approval was required for this study (https://www.uniklinikum-jena.de/ethikkommission/ Antragstellung.html). Students indicated their consent to participate by completing the questionnaire.

\section{Consent for publication}

Not applicable.

\section{Competing interests}

The authors declare that they have no competing interests.

\section{Publisher's Note}

Springer Nature remains neutral with regard to jurisdictional claims in published maps and institutional affiliations.

\section{Author details}

${ }^{1}$ Department of General, Visceral and Vascular Surgery, Universitätsklinikum Jena, Am Klinikum 1, 07747 Jena, Germany. ²Department of Gynaecology and Reproductive Medicine, Universitätsklinikum Jena, Am Klinikum 1, 07747 Jena, Germany. ${ }^{3}$ Department of General, Visceral and Vascular Surgery, Experimental Transplantation Surgery, Universitätsklinikum Jena, Drackendorfer Str. 1, 07747 Jena, Germany.

Received: 8 August 2018 Accepted: 23 April 2019 Published online: 15 May 2019

\section{References}

1. Patrício MF, Julião M, Fareleira F, Carneiro AV. Is the OSCE a feasible tool to assess competencies in undergraduate medical education? Med Teach. 2013:35:503-14

2. Boursicot K, Etheridge L, Setna Z, Sturrock A, Ker J, Smee S, Sambandam E. Performance in assessment: consensus statement and recommendations from the Ottawa conference. Med Teach. 2011;33:370-83.

3. Harden RM, Stevenson M, Downie WW, Wilson GM. Assessment of clinical competence using objective structured examination. Br Med J. 1975:1:447-51.

4. Harden RM. Misconceptions and the OSCE. Med Teach. 2015;37:608-10.
5. Walters K, Osborn D, Raven P. The development, validity and reliability of a multimodality objective structured clinical examination in psychiatry. Med Educ. 2005;39:292-8.

6. Gilson GJ, George KE, Qualls CM, Sarto GE, Obenshain SS, Boulet J. Assessing clinical competence of medical students in women's health care: use of the objective structured clinical examination. Obstet Gynecol. 1998;92:1038-43.

7. Matsell DG, Wolfish NM, Hsu E. Reliability and validity of the objective structured clinical examination in paediatrics. Med Educ. 1991;25:293-9.

8. Petrusa ER, Blackwell TA, Rogers LP, Saydjari C, Parcel S, Guckian JC. An objective measure of clinical performance. Am J Med. 1987;83:34-42.

9. Pierre RB, Wierenga A, Barton M, Branday JM, Christie CDC. Student evaluation of an OSCE in paediatrics at the University of the West Indies, Jamaica. BMC Med Educ. 2004:4:22.

10. Wilkinson TJ, Newble DI, Wilson PD, Carter JM, Helms RM. Development of a three-centre simultaneous objective structured clinical examination. Med Educ. 2000;34:798-807.

11. Newble DI. Eight years' experience with a structured clinical examination. Med Educ. 1988:22:200-4.

12. Newble DI, Jaeger $K$. The effect of assessments and examinations on the learning of medical students. Med Educ. 1983;17:165-71.

13. Mavis BE. Does studying for an objective structured clinical examination make a difference? Med Educ. 2000;34:808-12.

14. Rudland J, Wilkinson T, Smith-Han K, Thompson-Fawcett M. "You can do it late at night or in the morning. You can do it at home, I did it with my flatmate." The educational impact of an OSCE. Med Teach. 2008;30:206-11.

15. Hoffman KG, Donaldson JF. Contextual tensions of the clinical environment and their influence on teaching and learning. Med Educ 2004:38:448-54.

16. Approbationsordnung für Ärzte [National medical licensure act]. 2002. https://www.gesetze-im-internet.de/_appro_2002/BJNR240500002.html. Accessed 30 May 2018.

17. Müller S, Dahmen U, Settmacher U. Application of the objective structured clinical examination (OSCE) in German medical schools: an inventory. Gesundheitswesen. 2018:80:1099-103.

18. Destatis: Bildung und Kultur - Studierende an Hochschulen [Education and culture - students in higher education]. https://www.destatis.de/GPStatistik/ servlets/MCRFileNodeServlet/DEHeft_derivate_00016700/2110410157004.pdf Accessed 29 Apr 2019.

19. Müller S, Settmacher U, Koch I, Dahmen U. A pilot survey of student perceptions on the benefit of the OSCE and MCQ modalities. GMS J Med Educ 2018:35:Doc51.

20. Broekkamp H, van Hout-Wolters BHAM. Students' adaptation of study strategies when preparing for classroom tests. Educ Psychol Rev. 2007;19:401-28.

21. Biggs J. Assessing learning quality: reconciling institutional, staff and educational demands. Assess Eval High Educ. 1996;21:5-16.

22. Cilliers FJ, Schuwirth LWT, van der Vleuten CPM. A model of the preassessment learning effects of assessment is operational in an undergraduate clinical context. BMC Med Educ. 2012;12:9.

23. Kowlowitz V, Hoole AJ, Sloane PD. Implementing the objective structured clinical examination in a traditional medical school. Acad Med. 1991;66:345-7.

24. Johnson G, Reynard K. Assessment of an objective structured clinical examination (OSCE) for undergraduate students in accident and emergency medicine. J Accid Emerg Med. 1994;11:223-6.

25. Duvivier RJ, van Geel K, van Dalen J, Scherpbier AJJA, van der Vleuten CPM. Learning physical examination skills outside timetabled training sessions: what happens and why? Adv Health Sci Educ Theory Pract. 2012;17:339-55.

26. Durning SJ, Artino AR. Situativity theory: a perspective on how participants and the environment can interact: AMEE guide no. 52. Med Teach. 2011;33:188-99.

27. Mann KV. Theoretical perspectives in medical education: past experience and future possibilities. Med Educ. 2011;45:60-8

28. Khan KZ, Ramachandran S, Gaunt K, Pushkar P. The objective structured clinical examination (OSCE): AMEE guide no. 81. Part I: an historical and theoretical perspective. Med Teach. 2013;35:e1437-46.

29. Wallenstein J, Heron S, Santen S, Shayne P, Ander D. A core competencybased objective structured clinical examination (OSCE) can predict future resident performance. Acad Emerg Med. 2010;17(Suppl 2):67-71. 
30. Probert CS, Cahill DJ, McCann GL, Ben-Shlomo Y. Traditional finals and OSCEs in predicting consultant and self-reported clinical skills of PRHOs: a pilot study. Med Educ. 2003;37:597-602.

31. Khan K, Ramachandran S. Conceptual framework for performance assessment: competency, competence and performance in the context of assessments in healthcare - deciphering the terminology. Med Teach. 2012;34:920-8.

Ready to submit your research? Choose BMC and benefit from:

- fast, convenient online submission

- thorough peer review by experienced researchers in your field

- rapid publication on acceptance

- support for research data, including large and complex data types

- gold Open Access which fosters wider collaboration and increased citations

- maximum visibility for your research: over $100 \mathrm{M}$ website views per year

At $B M C$, research is always in progress.

Learn more biomedcentral.com/submissions 